\title{
Slip Resistance of Ti-Based High-Temperature Shape Memory Alloys
}

\author{
A. Ojha ${ }^{1} \cdot$ H. Sehitoglu ${ }^{1}$
}

Published online: 5 February 2016

(C) ASM International 2016

\begin{abstract}
Titanium with $\mathrm{Nb}, \mathrm{Zr}$, and Ta alloying substitutions possesses high plastic slip resistance and high transformation strains upon bcc $(\beta)$ to orthorhombic $\left(\alpha^{\prime \prime}\right)$ transformation. In the current study, we determine the critical resolved shear stress (CRSS) for slip in Ti alloyed for a wide composition range of $\mathrm{Nb}, \mathrm{Ta}$, and $\mathrm{Zr}$. The CRSS is obtained with a proposed Peierls-Nabarro formalism incorporating the generalized stacking fault energy barrier profile for slip obtained from the first-principles Density Functional Theory (DFT) calculations. The CRSS for slip of the orthorhombic martensite increases from 80 to $280 \mathrm{MPa}$ linearly with increasing unstable fault energy. The addition of tantalum is most effective in raising the energy barriers. We also demonstrate the composition dependence of the lattice parameters of both $\beta$ and $\alpha^{\prime \prime}$ crystal structures as a function of $\mathrm{Nb}, \mathrm{Ta}$, and $\mathrm{Zr}$ additions showing agreement with experiments. Using the lattice constants, the transformation strain is determined as high as $11 \%$ in the [011] pole and its magnitude increases mainly with $\mathrm{Zr}$ addition.
\end{abstract}

Keywords Shape memory $\cdot$ Superelasticity $\cdot \mathrm{Ti}-\mathrm{Nb}-\mathrm{Ta} \cdot$ $\mathrm{Ti}-\mathrm{Nb}-\mathrm{Zr} \cdot$ Transformation strain $\cdot$ Slip $\cdot$ Martensite

H. Sehitoglu

huseyin@illinois.edu

1 Department of Mechanical Science and Engineering, University of Illinois at Urbana-Champaign, $1206 \mathrm{~W}$. Green Street, Urbana, IL 61801, USA

\section{Introduction}

It is now well accepted that high-temperature Ti-based alloys represent a formidable class of new shape memory alloys. The research on Ti-based shape memory alloys dates back to key works in the 1970s through the early 1980s [15]. These alloys can be used in biomedical applications $[6,7]$ in addition to exhibiting high-temperature shape memory response [8-11]. Upon alloying with $\mathrm{Nb}, \mathrm{Zr}$, and $\mathrm{Ta}$, high slip resistance and high transformation strains can be achieved $[8,9,11,12]$, and improving such properties is a topic of continued scientific and engineering interest. While a number of key works listed above have emphasized experiments, less work has focused on theory and simulation. For example, the plastic slip resistance is a very important parameter in constitutive modeling [13] and to achieve good shape memory functionality and fatigue resistance. In order to minimize the plastic deformation mediated via dislocation slip, it is desirable to elevate the slip stress well above the stress required to induce martensite transformation. Experiments $[9,11,12]$ on $\mathrm{Ti}$ alloys demonstrate considerable martensite slip resistance particularly when alloyed with $\mathrm{Zr}, \mathrm{Nb}$ and $\mathrm{Ta}$. In addition, the slip stress magnitudes reported from these experiments are uniaxial stress magnitudes with $0.2 \%$ strain offset, and not the CRSS levels for slip nucleation. Hence, it is imperative to establish the composition dependence of the CRSS for slip nucleation in Ti-based alloys over a wide composition range of $\mathrm{Zr}, \mathrm{Nb}$, and $\mathrm{Ta}$. Most importantly, a quantitative model has not emerged that predicts the slip resistance over a broad range of compositions. This information is crucial for the design of new alloys and is the topic of this paper.

The present work represents a significant advancement in establishing the CRSS ( $\tau_{\text {critical }}^{\text {slip }}$ ) for martensite slip, the 
lattice constants $\left(a_{0}, a, b, c\right)$, and maximum transformation strains $\left(\varepsilon_{\text {trans }}^{\max }\right)$ of a large number of Ti-based shape memory alloys which have never been explored before. The $\mathrm{Nb}, \mathrm{Ta}$, and $\mathrm{Zr}$ contents for $\mathrm{Ti}$ alloys under current investigation range from 6.25 to 37.5 at.\% exceeding over 40 different compositions. In the present paper, we point to the major differences of alloying effects of $\mathrm{Zr}$, $\mathrm{Ta}$, and $\mathrm{Nb}$ on the CRSS and the transformation strains by considering the role of each element in detail. The CRSS for martensite slip is achieved with a proposed Peierls Nabarro (PN) formalism incorporating the generalized stacking fault energy (GSFE) obtained from first-principles energy calculations (DFT). The GSFE is the energy barrier per unit area required to nucleate a slip, and will be discussed later. Similarly, we establish the lattice constants of $\beta$ (disordered bcc) and B19 $\alpha^{\prime \prime}$ (orthorhombic) phases of these alloys noting that the superelasticity in $\mathrm{Ti}$ alloys is achieved by the reversible thermoelastic martensite transformation between these two phases. Hereafter, the terms B19, orthorhombic and $\alpha^{\prime \prime}$ are used interchangeably. In addition, we investigate the composition dependence of the $\mathrm{Nb}, \mathrm{Ta}$, and $\mathrm{Zr}$ on the lattice constants of both crystal phases. Consequently, we undertake lattice deformation theory (LDT) calculations to obtain the maximum transformation strains of all the alloys considered in the present analysis. The details of the LDT will be discussed later.

Although binary $\mathrm{Ti}-\mathrm{Nb}$ alloys exhibit superelastic properties, the transformation strains obtained for these alloys have been limited to less than $3 \%$ [10]. However, the maximum transformation strain of over $4.3 \%$ was obtained for the case of Ti-22Nb-(4-6)at.\% Zr [12], and the experimental results confirmed that $\mathrm{Zr}$ addition increases the maximum transformation strain and the martensite slip stress. Consequently, the combination of high transformation strains, plastic slip resistance, and high-temperature shape memory capability make these alloys very attractive for potential applications. Some of the compositions have been studied before, but many others are investigated in the current paper, which are very promising. Therefore, we establish the CRSS for these alloys with a wider composition range of $\mathrm{Nb}, \mathrm{Ta}$ and $\mathrm{Zr}$ that produce both a high slip resistance and a high transformation strain. We note that that the variation of slip resistance with increase in alloying content is highly nonlinear, and this necessitates an accurate model for flow stress, which we propose in this study.

The determination of the lattice parameters as a first step is not trivial because there are three lattice constants $(a, b$, $c$ ) for martensite, which are established for different levels of volume change by conducting multiple simulations with first-principles DFT calculations. In "Simulation Methods" and "Lattice Constant Calculations" sections, we present a detailed methodology to obtain the lattice constants of $\beta$ austenite and $\alpha^{\prime \prime}$ martensite phase of a group of $\mathrm{Ti}-\mathrm{Nb}-\mathrm{Ta}$ and $\mathrm{Ti}-\mathrm{Nb}-\mathrm{Zr}$ alloys using DFT calculations. In "Slip and GSFE Curves in B19 Ti Based Alloys" section, we provide discussion on obtaining the GSFE for B19 (martensite) slip nucleation and the modified PN methodology to establish the CRSS for these alloys. We provide discussion and the implications of results in "Discussion and Implications of Results" section, and finally provide a summary in "Conclusions" section.

\section{Simulation Methods}

The first-principles DFT calculations were carried out to calculate the systems total energy. We utilized the Vienna ab initio Simulations Package (VASP) with the projector augmented wave (PAW) method and the generalized gradient approximation (GGA) as implementations of DFT $[14,15]$. In order to simulate a disordered $\beta$ crystal, a simulator code was implemented to generate a $4 \times 4 \times 2$ supercell consisting of 64 atoms. The three atom types ( $\mathrm{Ti}$, $\mathrm{Nb}$, and $\mathrm{Ta} / \mathrm{Zr}$ ) were positioned randomly within the supercell yet following the composition and the bcc crystal coordinates so that the two atomic positions do not overlap with each other. It is important to note that 64 atoms supercell was large enough to obtain the converged minimum structural energy value. This was verified with independent simulations with number of atoms ranging from 16 to 96. In addition, four independent cases representing four different random solid solution alloys were investigated to see the effect of the positions of the elements on the lattice constants and the minimum structural energies. The variation of the lattice constant and the structural energy due to random alloy positioning was within $0.5 \%$ agreement. In our calculations, we used a $6 \times 6 \times 12$ Monkhorst-Pack $k$-point meshes for the Brillouin-zone integration to ensure the convergence of the results. For uniform sampling of the $k$-space, note that the $k$ points chosen are inversely proportional to the ratio of the lattice vectors of the supercell. The $k$ points chosen in the current simulation were verified to yield a converged minimum energy value. Similar procedure was followed for GSFE calculations of B19 orthorhombic structure. Ionic relaxation was performed by a conjugate gradient algorithm. The energy cut-off of $360 \mathrm{eV}$ was used for the plane-wave basis set. The total energy was converged to less than $10^{-5} \mathrm{eV}$ per atom. For GSFE calculations, a full internal atom relaxation, including perpendicular and parallel directions to the fault plane, was allowed for minimizing the short-range interaction between misfitted layers in the vicinity of the fault plane. During the relaxation 
process, the total energy of the deformed crystal was minimized.

\section{Results}

\section{Lattice Constant Calculations}

In this section, we demonstrate a general methodology to obtain the lattice constants for the $\beta$ and $\alpha^{\prime \prime}$ crystal structures in detail. We take Ti-6.25Nb-31.25Zr as an example case (note that the compositions used hereafter are all atomic percentage). In order to derive the $\beta$ lattice constant, the total structural energies of the $\beta$ supercell are first obtained by varying the lattice parameters. Then the equilibrium lattice constant $\left(a_{0}\right)$ is taken as the one corresponding to the minimum structural energy as shown in Fig. 1. Using this methodology, the equilibrium lattice constant of $\mathrm{Ti}-6.25 \mathrm{Nb}-31.25 \mathrm{Zr}$ is calculated as $3.35 \AA$.

Since an orthorhombic $\left(\alpha^{\prime \prime}\right)$ crystal has three different lattice parameters, $a, b$, and $c$ for the angles $\alpha=\beta=\gamma=90^{\circ}$, it is first important to obtain the equilibrium volume. In all the B19 crystals considered, ' $a$ ' is the smallest, ' $b$ ' is the intermediate, and ' $c$ ' is the largest lattice parameter. Figure 2 shows the structural energy variation with respect to different volumes for the case of Ti-6.25Nb-31.25Zr, and the calculated equilibrium volume is $76 \AA^{3}$. For a constant equilibrium volume, it is now convenient to obtain the structural energy of the crystal by varying only two parameters, $a / c$ and $b / c$ ratios. We note that the ratios, $a / c=0.59$ and $b / c=0.92$, correspond to the lowest energy for the case of $\mathrm{Ti}-6.25 \mathrm{Nb}-31.25 \mathrm{Zr}$, as shown in potential energy surface of Fig. 3. Hence, the equilibrium lattice constants $a, b$, and $c$ can be obtained

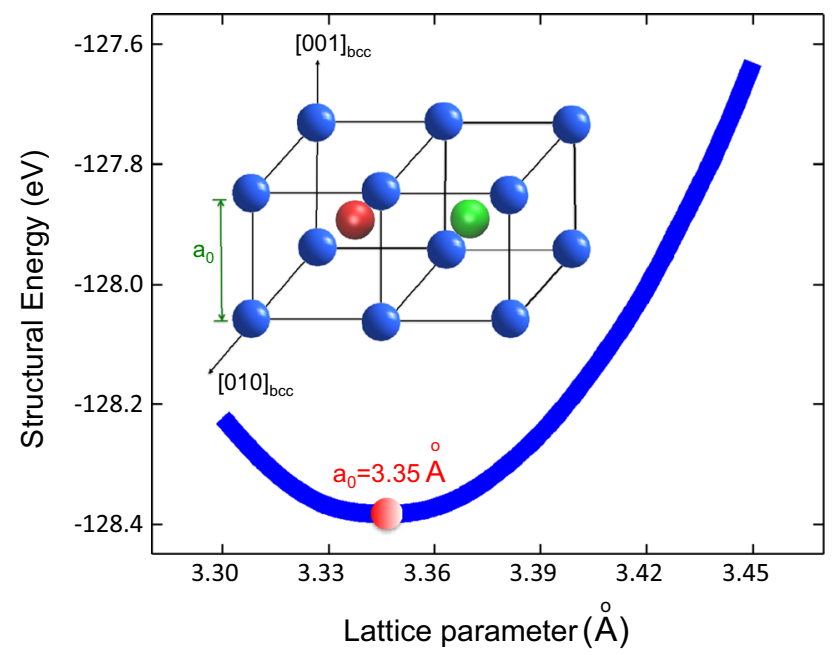

Fig. 1 Structural energy variation with respect to lattice parameters for $\mathrm{Ti}-6.25 \mathrm{Nb}-31.25 \mathrm{Zr}$ alloy

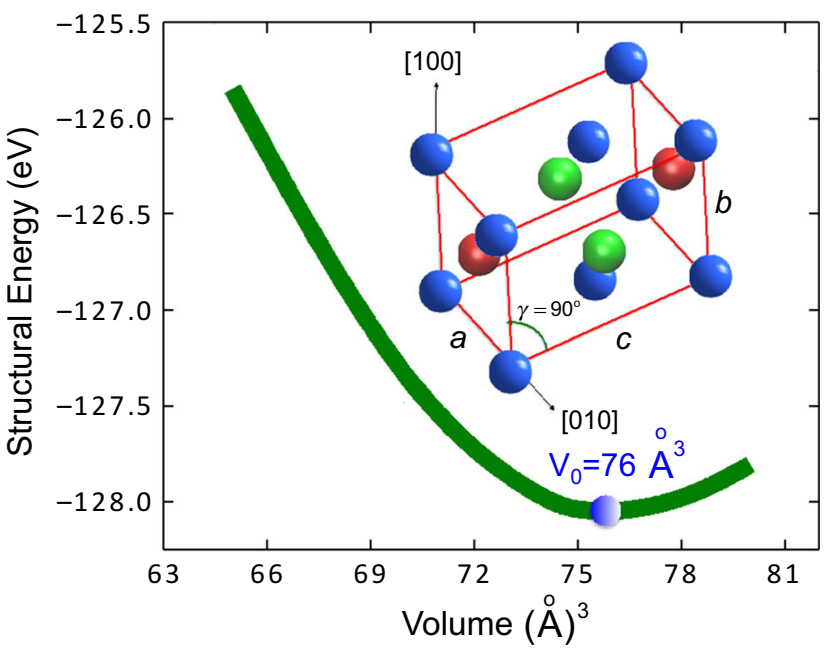

Fig. 2 Structural energy variation with respect to volume change for a B19 Ti-6.25Nb-31.25Zr crystal

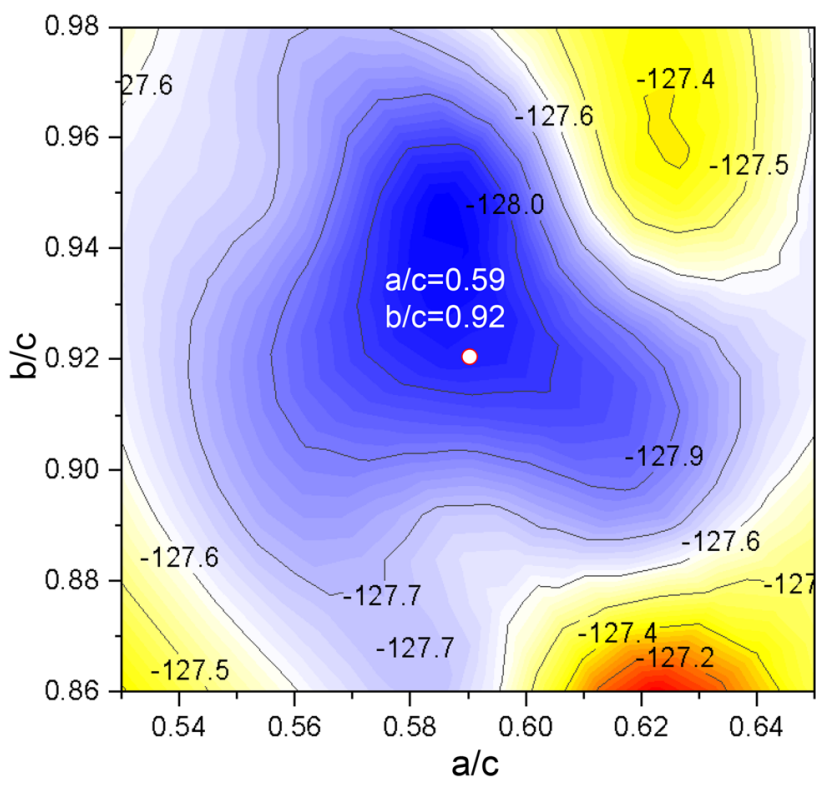

Fig. 3 Energy (in eV) versus $a / c$ and $b / c$ ratios under constant equilibrium volume for a $\mathrm{B} 19 \mathrm{Ti}-6.25 \mathrm{Nb}-31.25 \mathrm{Zr}$ crystal

from the knowledge of equilibrium volume and the lattice parameters' ratios. We used similar methodology to calculate the lattice constants for all other alloys considered in the present study. A comprehensive list of lattice parameters for $\mathrm{Ti}-\mathrm{Nb}-\mathrm{Zr}$ and $\mathrm{Ti}-\mathrm{Nb}-\mathrm{Ta}$ alloys for both $\beta$ and $\mathrm{B} 19$ $\alpha^{\prime \prime}$ structures is listed in Tables 1 and 2 .

To further study the composition dependence of $\mathrm{Nb}, \mathrm{Zr}$, and Ta on the $\beta$ and B19 $\alpha^{\prime \prime}$ lattice parameters, we plot the results of Tables 1 and 2 in Figs. 4, 5, and 6. It is important to note that the theoretical values reported in Figs. 4, 5, and 6 are in excellent agreement with the experimentally observed values (within $3 \%$ ) [8]. Figure 4 shows that the $\beta$ 
Table 1 Lattice constant $\left(a_{0}\right)$ of $\beta$ and orthorhombic phases $(a, b, c)$ of Ti-Nb-Zr alloys. The units are in Angstroms

\begin{tabular}{|c|c|c|c|c|c|c|c|c|}
\hline \multirow[t]{2}{*}{ Alloys } & \multicolumn{4}{|c|}{ Theory (this study) } & \multicolumn{4}{|c|}{ Experiments } \\
\hline & $a_{0}$ & $a$ & $b$ & $c$ & $a_{0}$ & $a$ & $b$ & $c$ \\
\hline $\mathrm{Ti}-12.5 \mathrm{Nb}$ & 3.26 & 3.01 & 4.65 & 4.95 & 3.285 & 3.02 & 4.661 & 4.985 \\
\hline $\mathrm{Ti}-25 \mathrm{Nb}$ & 3.26 & 3.17 & 4.62 & 4.76 & 3.285 & 3.193 & 4.635 & 4.797 \\
\hline $\mathrm{Ti}-6.25 \mathrm{Nb}-6.25 \mathrm{Zr}$ & 3.28 & 3.03 & 4.79 & 5.17 & - & - & - & - \\
\hline $\mathrm{Ti}-25 \mathrm{Nb}-6.25 \mathrm{Zr}$ & 3.28 & 3.24 & 4.65 & 4.81 & 3.30 & $3.25^{\mathrm{a}}$ & 4.66 & 4.83 \\
\hline $\mathrm{Ti}-12.5 \mathrm{Nb}-12.5 \mathrm{Zr}$ & 3.29 & 3.08 & 4.73 & 5.01 & & $3.09^{\mathrm{b}}$ & 4.75 & 5.03 \\
\hline $\mathrm{Ti}-18.75 \mathrm{Nb}-12.5 \mathrm{Zr}$ & 3.29 & 3.17 & 4.66 & 4.89 & 3.32 & $3.19^{\mathrm{c}}$ & 4.68 & 4.90 \\
\hline $\mathrm{Ti}-37.25 \mathrm{Nb}-12.5 \mathrm{Zr}$ & 3.29 & 3.27 & 4.62 & 4.85 & - & - & - & - \\
\hline Ti-6.25Nb-18.75Zr & 3.31 & 3.04 & 4.79 & 5.18 & - & - & - & - \\
\hline $\mathrm{Ti}-12.5 \mathrm{Nb}-25 \mathrm{Zr}$ & 3.33 & 3.16 & 4.76 & 5.02 & 3.36 & $3.18^{\mathrm{d}}$ & 4.79 & 5.03 \\
\hline $\mathrm{Ti}-18.75 \mathrm{Nb}-25 \mathrm{Zr}$ & 3.33 & 3.18 & 4.67 & 4.90 & - & - & - & - \\
\hline Ti-25Nb-25Zr & 3.33 & 3.23 & 4.65 & 4.81 & - & - & - & - \\
\hline $\mathrm{Ti}-6.25 \mathrm{Nb}-31.25 \mathrm{Zr}$ & 3.35 & 3.06 & 4.80 & 5.21 & 3.386 & $3.09^{\mathrm{e}}$ & 4.82 & 5.22 \\
\hline $\mathrm{Ti}-12.5 \mathrm{Nb}-37.5 \mathrm{Zr}$ & 3.38 & 3.18 & 4.77 & 5.03 & - & - & - & - \\
\hline $\mathrm{Ti}-37.5 \mathrm{Nb}-18.75 \mathrm{Zr}$ & 3.31 & 3.28 & 4.63 & 4.86 & - & - & - & - \\
\hline Ti-12.5Nb-18.75Zr & 3.31 & 3.08 & 4.70 & 4.98 & - & - & - & - \\
\hline $\mathrm{Ti}-18.75 \mathrm{Nb}$ & 3.26 & 3.09 & 4.63 & 4.87 & - & - & - & - \\
\hline $\mathrm{Ti}-18.75 \mathrm{Nb}-6.25 \mathrm{Zr}$ & 3.28 & 3.17 & 4.64 & 4.87 & - & - & - & - \\
\hline
\end{tabular}

The spaces marked with dash (-) represent unavailable experimental data. Approximate values based on the following compositions [8]

a $\mathrm{Ti}-20 \mathrm{Nb}-6 \mathrm{Zr}$

b $\mathrm{Ti}-13 \mathrm{Nb}-12 \mathrm{Zr}$

c $\mathrm{Ti}-16 \mathrm{Nb}-12 \mathrm{Zr}$

d $\mathrm{Ti}-10 \mathrm{Nb}-24 \mathrm{Zr}$

e $\mathrm{Ti}-6 \mathrm{Nb}-30 \mathrm{Zr}$

Table 2 Lattice constant $\left(a_{0}\right)$ of $\beta$ and orthorhombic phases $(a, b, c)$ of Ti-Ta-Nb alloys. The units are in Angstroms

\begin{tabular}{|c|c|c|c|c|c|c|c|c|}
\hline \multirow[t]{2}{*}{ Alloys } & \multicolumn{4}{|c|}{ Theory (this study) } & \multicolumn{4}{|c|}{ Experiments } \\
\hline & $a_{0}$ & $a$ & $b$ & $c$ & $a_{0}$ & $a$ & $b$ & $c$ \\
\hline $\mathrm{Ti}-6.25 \mathrm{Nb}-6.25 \mathrm{Ta}$ & 3.26 & 3.06 & 4.66 & 4.93 & - & - & - & - \\
\hline $\mathrm{Ti}-25 \mathrm{Nb}-6.25 \mathrm{Ta}$ & 3.26 & 3.11 & 4.66 & 4.77 & - & - & - & - \\
\hline $\mathrm{Ti}-12.5 \mathrm{Nb}-12.5 \mathrm{Ta}$ & 3.27 & 3.15 & 4.65 & 4.84 & - & $3.17^{\mathrm{a}}$ & 4.65 & 4.85 \\
\hline $\mathrm{Ti}-18.75 \mathrm{Nb}-12.5 \mathrm{Ta}$ & 3.26 & 3.19 & 4.64 & 4.76 & 3.28 & $3.21^{\mathrm{b}}$ & 4.64 & 4.78 \\
\hline $\mathrm{Ti}-37.25 \mathrm{Nb}-12.5 \mathrm{Ta}$ & 3.26 & 3.25 & 4.64 & 4.73 & - & - & - & - \\
\hline $\mathrm{Ti}-6.25 \mathrm{Nb}-18.75 \mathrm{Ta}$ & 3.26 & 3.15 & 4.64 & 4.81 & - & $3.16^{\mathrm{c}}$ & 4.64 & 4.83 \\
\hline $\mathrm{Ti}-12.5 \mathrm{Nb}-25 \mathrm{Ta}$ & 3.27 & 3.26 & 4.65 & 4.74 & - & - & - & - \\
\hline $\mathrm{Ti}-18.75 \mathrm{Nb}-25 \mathrm{Ta}$ & 3.26 & 3.27 & 4.66 & 4.72 & - & - & - & - \\
\hline $\mathrm{Ti}-25 \mathrm{Nb}-25 \mathrm{Ta}$ & 3.27 & 3.28 & 4.66 & 4.71 & - & - & - & - \\
\hline $\mathrm{Ti}-6.25 \mathrm{Nb}-31.25 \mathrm{Ta}$ & 3.25 & 3.23 & 4.63 & 4.72 & 3.28 & $3.26^{\mathrm{d}}$ & 4.64 & 4.73 \\
\hline $\mathrm{Ti}-12.5 \mathrm{Nb}-37.5 \mathrm{Ta}$ & 3.27 & 3.25 & 4.66 & 4.71 & - & - & - & - \\
\hline $\mathrm{Ti}-37.5 \mathrm{Nb}-18.75 \mathrm{Ta}$ & 3.27 & 3.26 & 4.67 & 4.74 & - & - & - & - \\
\hline
\end{tabular}

The spaces marked with dash (-) represent unavailable experimental data. Approximate values based on the following compositions [8]

a $\mathrm{Ti}-14 \mathrm{Nb}-10 \mathrm{Ta}$

b $\mathrm{Ti}-17 \mathrm{Nb}-10 \mathrm{Ta}$

c $\mathrm{Ti}-6.25 \mathrm{Nb}-20 \mathrm{Ta}$

d $\mathrm{Ti}-6.25 \mathrm{Nb}-30 \mathrm{Ta}$ 


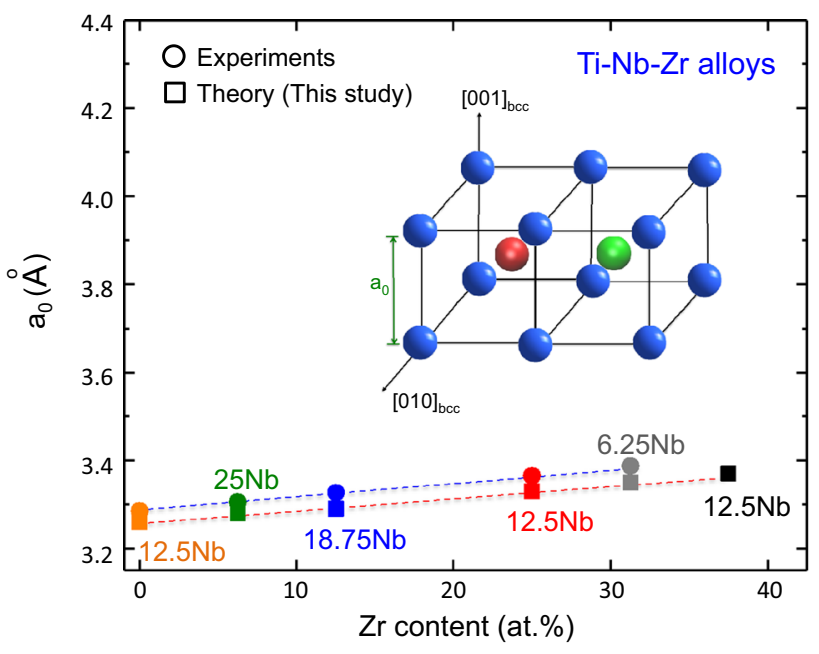

Fig. 4 Lattice constant of $\mathrm{Ti}-\mathrm{Nb}-\mathrm{Zr}$ alloys versus $\mathrm{Zr}$ composition. The broken lines are shown to aid the eye

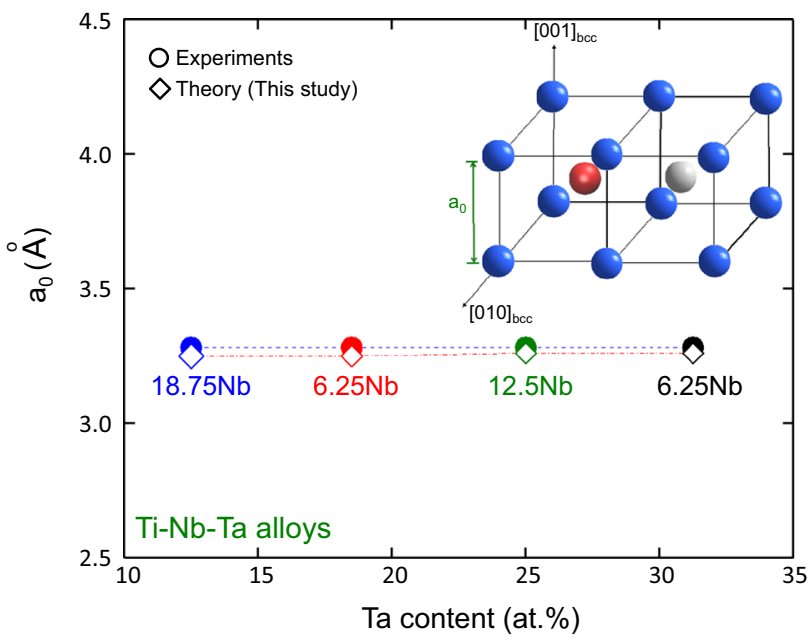

Fig. 5 Lattice constants of $\mathrm{Ti}-\mathrm{Nb}-\mathrm{Ta}$ alloys versus $\mathrm{Ta}$ composition. The broken lines are shown to guide the eye

phase lattice constants $\left(a_{0}\right)$ for Ti-Nb-Zr alloys are strongly dependent on the $\mathrm{Zr}$ content. An increase in the $\mathrm{Zr}$ content linearly increases $a_{0}$, and the relationship between $\mathrm{Zr}$ content and $a_{0}$ can be expressed as follows:

$a_{0}(\mathrm{Zr}$ at. $\%)=3.2585+0.0029 \times C_{\mathrm{Zr}(\mathrm{at} . \%)}$,

where $C$ is the concentration of $\mathrm{Zr}$ in at.\%. On the other hand, in Fig. 5, we observe that both $\mathrm{Nb}$ and $\mathrm{Ta}$ do not have a considerable effect on $a_{0}$ for Ti-Nb-Ta alloys.

In order to investigate the effects of $\mathrm{Nb}$ content on the orthorhombic (B19) lattice parameters, we plot $a, b$, and $c$ as a function of $\mathrm{Nb}$ content for some of the alloys listed in Table 1 where experimental data [8] are also available. Interestingly, from Fig. 6, we see that the $\mathrm{Nb}$ content affects the B19 lattice constants. In particular, the lattice

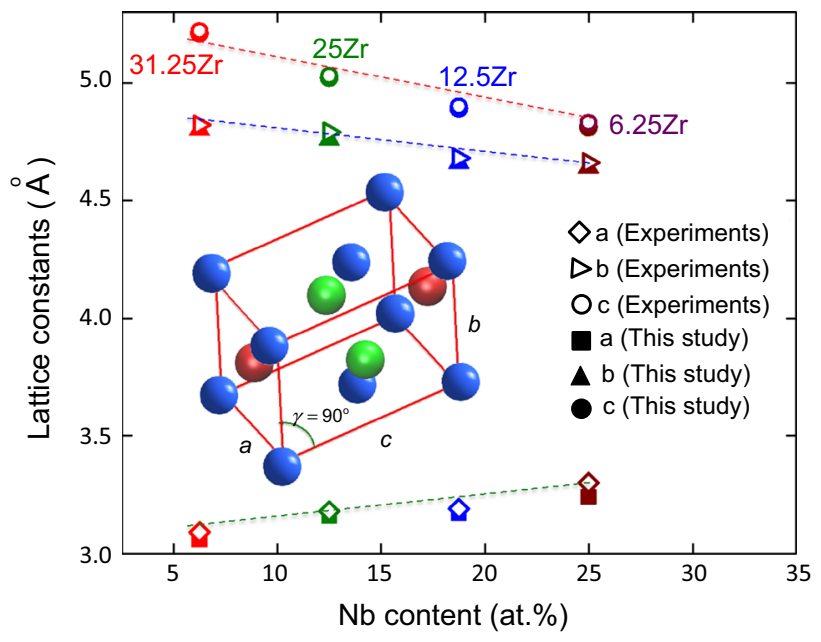

Fig. 6 Lattice constants $(a, b, c)$ of $\mathrm{B} 19 \mathrm{Ti}-\mathrm{Nb}-\mathrm{Zr}$ alloys versus $\mathrm{Nb}$ content

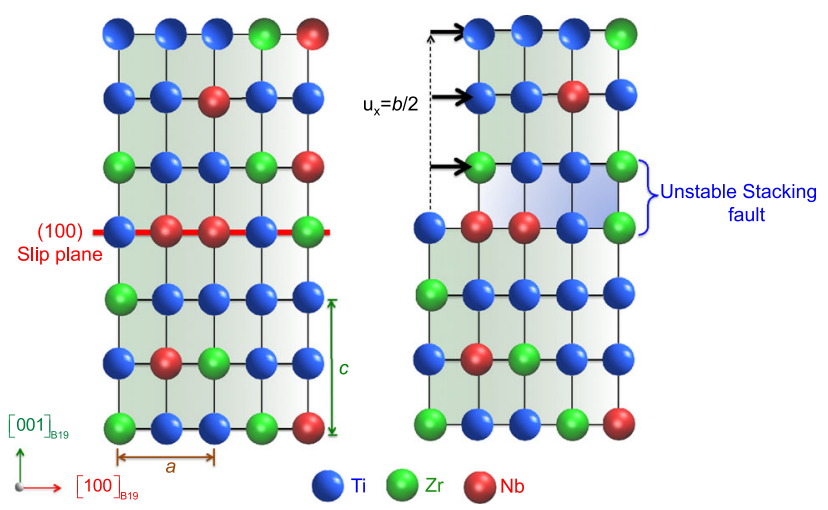

(a)

(b)

Fig. 7 a A perfect B19 lattice as viewed along the $\langle 010\rangle$ direction. b Deformed B19 lattice after shear by half the magnitude of Burgers vector $\left(u_{\mathrm{x}}=b / 2\right)$

parameter $a$ increases, while $b$ and $c$ decrease with an increase in $\mathrm{Nb}$ content regardless of the $\mathrm{Zr}$ content in these alloys. These observations are validated both experimentally and theoretically in Fig. 6.

\section{Slip and GSFE Curves in B19 Ti-Based Alloys}

An important criterion to maximize reversible strain is to minimize plastic deformation accumulating via dislocation slip in $\alpha^{\prime \prime}$ martensite during phase transformation. The possible slip systems in B19 orthorhombic crystal structures include a family of $\{110\}\langle 110\rangle$ and $\{100\}\langle 100\rangle$ systems [16, 17]. Consider Fig. 7a where the B19 crystal structure is shown as viewed along the $[0 \overline{1} 0]$ direction. It is worth pointing out that in Fig. $7 \mathrm{a}$, the slip system (001)[100] corresponds to the largest interplanar distance (axis $c$ ) in [001] direction and the shortest Burgers vector 
(axis $a$ ) in [100] direction. Based on this slip system, the Burgers vector $(b)$ for $\mathrm{B} 19 \mathrm{Ti}-6.25 \mathrm{Zr}-25 \mathrm{Nb}$ lattice is equal to $3.24 \AA$, for example.

The GSFE is obtained by shearing one half (001) plane of the crystal with respect to another half by continuous rigid displacements of $u_{\mathrm{x}}=n b$ along [100] direction, where $b$ is the magnitude of the Burgers vector and $n$ is a parameter ranging from 0 to 1 [18-20]. Similarly, Fig. $7 \mathrm{~b}$ is the deformed lattice after shear by half a Burgers vector $\left(u_{\mathrm{x}}=0.5 b\right)$. The GSFE curves for both alloy systems, Ti$\mathrm{Nb}-\mathrm{Ta}$ and $\mathrm{Ti}-\mathrm{Nb}-\mathrm{Zr}$, for four different compositions exhibiting the highest $\gamma_{\text {us }}$ values and the lowest $\gamma_{\text {us }}$ values are shown in Fig. 8. The $\gamma_{\mathrm{us}}$ is the maximum energy barrier required to nucleate a slip, and corresponds to the displacement of $u_{\mathrm{x}}=0.5 b$ on the GSFE curve. The (001)[100] $\gamma_{\mathrm{us}}$ values for each alloy considered in the present analysis are reported in Table 3, and graphically represented in Fig. 8. The GSFE curve also allows us to derive the $\{100\}\langle 100\rangle$ shear modulus using the equation, $G_{\{100\}\langle 100\rangle}=\left.2 \pi \frac{\partial \gamma}{\partial u}\right|_{\max }$. The magnitudes of the shear moduli for $\mathrm{Ti}-\mathrm{Nb}-\mathrm{Zr}$ and $\mathrm{Ti}-$ $\mathrm{Nb}-\mathrm{Ta}$ alloys are also listed in Table 3 .

In the present analysis, we determined that the $\{100\}\langle 100\rangle$ are the active slip systems in Ti-Nb-Zr and Ti$\mathrm{Nb}$-Ta alloys. We also obtained the GSFE curves for $\{110\}\langle 110\rangle$ slip systems using similar methodology discussed above. The $\{110\}\langle 110\rangle \gamma_{\text {us }}$ values for all the alloys considered are approximately 3-5 times higher than those for $\{100\}\langle 100\rangle$ slip systems. For example, the $\{110\}\langle 110\rangle$ $\gamma_{\mathrm{us}}$ for $\mathrm{Ti}-6.25 \mathrm{Zr}-6.25 \mathrm{Nb}, \mathrm{Ti}-18.75 \mathrm{Zr}-37.5 \mathrm{Nb}$, Ti-25Ta$25 \mathrm{Nb}$, and $\mathrm{Ti}-6.25 \mathrm{Ta}-6.25 \mathrm{Nb}$ alloys were obtained as 922 , 2124,3276 , and $1613 \mathrm{~mJ} \mathrm{~m}^{-2}$, respectively. These values are significantly higher than the $\gamma_{\text {us }}$ for $\{100\}\langle 100\rangle$ slip

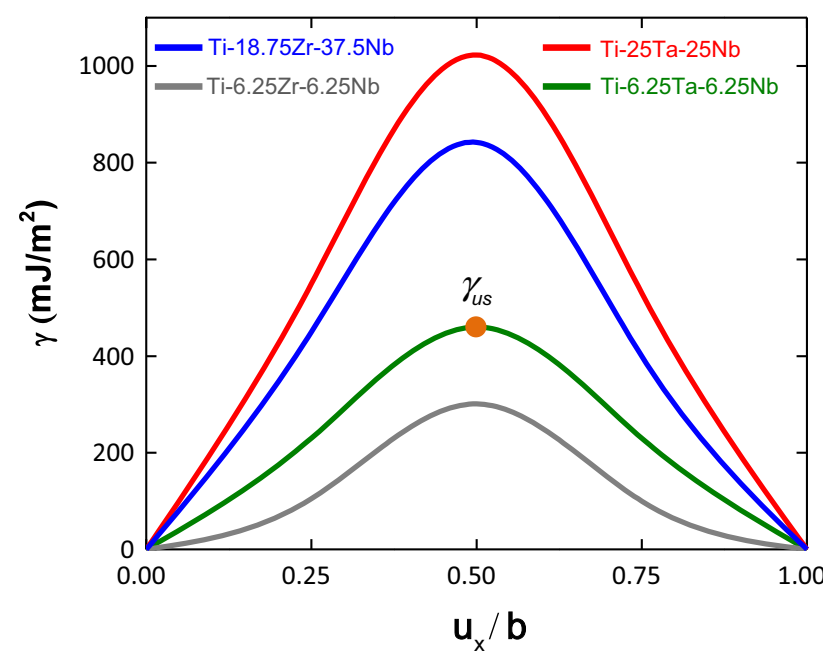

Fig. 8 Generalized stacking fault energy (GSFE) for Ti-Nb-Ta and $\mathrm{Ti}-\mathrm{Nb}-\mathrm{Zr}$ alloys for the compositions exhibiting the highest and the lowest values systems, and hence rule out the possibility of slip nucleation in $\{110\}\langle 110\rangle$ slip systems. Recently, similar theoretical calculations [21] on NiTiHf have shown that the activation of slip systems of $\{110\}\langle 110\rangle$ family in B19 lattice is unfavorable due to the high energy barrier associated with the generalized stacking fault energy (GSFE) curve, and ultimately high CRSS (in orders of GPa). Hence, the $\{100\}\langle 100\rangle$ slip system is considered for further analysis in the present paper.

Figure $9 a, b$ shows the ternary contour plot of $\gamma_{\text {us }}$ variation for $\mathrm{Ti}-\mathrm{Nb}-\mathrm{Zr}$ and $\mathrm{Ti}-\mathrm{Nb}-\mathrm{Ta}$ alloys. Upon comparing the plots, we observe that the $\gamma_{u s}$ values for all $\mathrm{Ti}-\mathrm{Nb}-\mathrm{Ta}$ alloys are higher than that of $\mathrm{Ti}-\mathrm{Nb}-\mathrm{Zr}$ alloys for the same composition of $\mathrm{Ti}$ and $\mathrm{Nb}$. For the case of $\mathrm{Ti}-\mathrm{Nb}-\mathrm{Zr}$ alloys, the maximum $\gamma_{\mathrm{us}}$ values lie in the region of high $\mathrm{Nb}$ and high $\mathrm{Zr}$ content, shown by as shown by red shades in Fig. 9a, while in the case of Ti-Nb-Ta alloys, the maximum $\gamma_{\text {us }}$ values are obtained in low $\mathrm{Nb}$ and high Ta content. The lower $\gamma_{\text {us }}$ values for $\mathrm{Ti}-\mathrm{Nb}-\mathrm{Zr}$ lie along the constant $\mathrm{Nb}$ content of 12.5 at.\%, while for $\mathrm{Ti}-\mathrm{Nb}-\mathrm{Ta}$ alloys, the region is observed in low $\mathrm{Ta}$ and low $\mathrm{Nb}$ content. As we see later, the magnitude of $\gamma_{\text {us }}$ influences the CRSS for martensite slip nucleation. Therefore, the results in Fig. 9 provide useful insights for slip resistance associated with different compositions of $\mathrm{Nb}, \mathrm{Ta}$, and $\mathrm{Zr}$ in $\mathrm{Ti}$ based alloys.

\section{Peierls Nabarro Modeling of the Critical Resolved Shear Stress (CRSS) for Slip}

The modified PN formalism is adopted in the current work to calculate the slip stress, which is an advancement to the original PN model [22, 23]. The major advancements of the modified PN formalism are the use of actual energy landscape (GSFE) of the alloy to calculate the energy variation with respect to the dislocation position and the consideration of the lattice discreteness to obtain the misfit energy curve [24-27]. The misfit energy across a slip plane is defined as the sum over energy contributions due to slip between pairs of atomic planes [26, 27], and can be obtained from the GSFE as follows:

$E_{\gamma}^{\mathrm{s}}=\int_{-\infty}^{+\infty} \gamma_{\mathrm{GSFE}}(f(x)) \mathrm{d} x$

The term $\gamma_{\text {GSFE }}$ is the GSFE energy landscape (as shown in Fig. 8) expressed in sinusoidal form, and $f(x)$ is defined as the disregistry function which is a measure of the slip distribution on the slip plane, $u_{\mathrm{A}}-u_{\mathrm{B}}$ as shown in Fig. 10a. The solution to $f(x)$ can be written as follows [26, 27]: 
Table 3 The $\gamma_{\mathrm{us}}$ values, the shear moduli, and the CRSS for slip nucleation in B19 Ti-Nb-Zr and Ti-Nb-Ta alloys

\begin{tabular}{|c|c|c|c|c|c|c|c|}
\hline $\begin{array}{l}\mathrm{Ti}-\mathrm{Nb}-\mathrm{Zr} \\
\text { Alloys (at.\%) }\end{array}$ & $\begin{array}{l}\gamma_{\text {us }} \\
\left(\mathrm{mJ} \mathrm{m} \mathrm{m}^{-2}\right)\end{array}$ & $\begin{array}{l}\text { Shear modulus (in } \\
\text { GPa) } \\
G_{\{100\}\langle 100\rangle}\end{array}$ & $\begin{array}{l}\text { CRSS, } \tau_{\text {critical }}^{\text {slip }} \\
(\mathrm{MPa})\end{array}$ & $\begin{array}{l}\text { Ti-Nb-Ta } \\
\text { Alloys (at.\%) }\end{array}$ & $\begin{array}{l}\gamma_{\text {us }} \\
\left(\mathrm{mJ} \mathrm{m}^{-2}\right)\end{array}$ & $\begin{array}{l}\text { Shear modulus (in } \\
\text { GPa) } \\
G_{\{100\}\langle 100\rangle}\end{array}$ & $\begin{array}{l}\text { CRSS, } \tau_{\text {critical }}^{\text {slip }} \\
(\mathrm{MPa})\end{array}$ \\
\hline $\begin{array}{l}\mathrm{Ti}-6.25 \mathrm{Nb}- \\
6.25 \mathrm{Zr}\end{array}$ & 301 & 11 & 82 & $\begin{array}{c}\mathrm{Ti}-6.25 \mathrm{Nb}- \\
6.25 \mathrm{Ta}\end{array}$ & 460 & 16 & 127 \\
\hline $\begin{array}{c}\mathrm{Ti}-6.25 \mathrm{Nb}- \\
18.75 \mathrm{Zr}\end{array}$ & 315 & 12 & 88 & $\begin{array}{c}\mathrm{Ti}-6.25 \mathrm{Nb}- \\
18.75 \mathrm{Ta}\end{array}$ & 550 & 20 & 152 \\
\hline $\begin{array}{l}\mathrm{Ti}-6.25 \mathrm{Nb}- \\
25 \mathrm{Zr}\end{array}$ & 386 & 14 & 109 & $\begin{array}{l}\mathrm{Ti}-6.25 \mathrm{Nb}- \\
25 \mathrm{Ta}\end{array}$ & 901 & 32 & 244 \\
\hline $\begin{array}{c}\mathrm{Ti}-6.25 \mathrm{Nb}- \\
31.25 \mathrm{Zr}\end{array}$ & 475 & 17 & 132 & $\begin{array}{c}\mathrm{Ti}-6.25 \mathrm{Nb}- \\
31.25 \mathrm{Ta}\end{array}$ & 912 & 32 & 250 \\
\hline $\mathrm{Ti}-12.5 \mathrm{Nb}$ & 532 & 18 & 144 & $\begin{array}{c}\mathrm{Ti}-12.5 \mathrm{Nb}- \\
6.25 \mathrm{Ta}\end{array}$ & 810 & 29 & 224 \\
\hline $\begin{array}{l}\mathrm{Ti}-12.5 \mathrm{Nb}- \\
6.25 \mathrm{Zr}\end{array}$ & 387 & 13 & 110 & $\begin{array}{c}\mathrm{Ti}-12.5 \mathrm{Nb}- \\
12.5 \mathrm{Ta}\end{array}$ & 953 & 34 & 263 \\
\hline $\begin{array}{l}\mathrm{Ti}-12.5 \mathrm{Nb}- \\
12.5 \mathrm{Zr}\end{array}$ & 311 & 11 & 86 & $\begin{array}{c}\mathrm{Ti}-12.5 \mathrm{Nb}- \\
18.75 \mathrm{Ta}\end{array}$ & 997 & 35 & 271 \\
\hline $\begin{array}{c}\mathrm{Ti}-12.5 \mathrm{Nb}- \\
18.75 \mathrm{Zr}\end{array}$ & 381 & 14 & 101 & $\begin{array}{l}\mathrm{Ti}-12.5 \mathrm{Nb}- \\
25 \mathrm{Ta}\end{array}$ & 1006 & 36 & 278 \\
\hline $\begin{array}{l}\mathrm{Ti}-12.5 \mathrm{Nb}- \\
25 \mathrm{Zr}\end{array}$ & 410 & 24 & 125 & $\begin{array}{c}\mathrm{Ti}-12.5 \mathrm{Nb}- \\
37.5 \mathrm{Ta}\end{array}$ & 1013 & 36 & 280 \\
\hline $\begin{array}{c}\mathrm{Ti}-12.5 \mathrm{Nb}- \\
37.5 \mathrm{Zr}\end{array}$ & 678 & 26 & 184 & $\begin{array}{l}\mathrm{Ti}-18.75 \mathrm{Nb}- \\
6.25 \mathrm{Ta}\end{array}$ & 805 & 29 & 222 \\
\hline $\begin{array}{c}\mathrm{Ti}-18.75 \mathrm{Nb}- \\
12.5 \mathrm{Zr}\end{array}$ & 752 & 27 & 190 & $\begin{array}{l}\mathrm{Ti}-18.75 \mathrm{Nb}- \\
12.5 \mathrm{Ta}\end{array}$ & 920 & 33 & 254 \\
\hline $\begin{array}{l}\mathrm{Ti}-18.75 \mathrm{Nb}- \\
25 \mathrm{Zr}\end{array}$ & 760 & 27 & 200 & $\begin{array}{c}\mathrm{Ti}-18.75 \mathrm{Nb}- \\
18.75 \mathrm{Ta}\end{array}$ & 922 & 33 & 255 \\
\hline $\mathrm{Ti}-25 \mathrm{Nb}$ & 843 & 29 & 228 & $\begin{array}{l}\mathrm{Ti}-18.75 \mathrm{Nb}- \\
25 \mathrm{Ta}\end{array}$ & 923 & 33 & 255 \\
\hline $\begin{array}{c}\mathrm{Ti}-25 \mathrm{Nb}- \\
6.25 \mathrm{Zr}\end{array}$ & 754 & 26 & 195 & $\begin{array}{c}\mathrm{Ti}-25 \mathrm{Nb}- \\
6.25 \mathrm{Ta}\end{array}$ & 857 & 31 & 237 \\
\hline $\begin{array}{c}\mathrm{Ti}-25 \mathrm{Nb}- \\
12.5 \mathrm{Zr}\end{array}$ & 756 & 27 & 196 & $\begin{array}{c}\mathrm{Ti}-25 \mathrm{Nb}- \\
12.5 \mathrm{Ta}\end{array}$ & 950 & 34 & 261 \\
\hline $\mathrm{Ti}-25 \mathrm{Nb}-25 \mathrm{Zr}$ & 787 & 28 & 206 & $\begin{array}{c}\mathrm{Ti}-25 \mathrm{Nb}- \\
18.75 \mathrm{Ta}\end{array}$ & 1011 & 36 & 280 \\
\hline $\mathrm{Ti}-37.5 \mathrm{Nb}$ & 852 & 31 & 231 & $\mathrm{Ti}-25 \mathrm{Nb}-25 \mathrm{Ta}$ & 1023 & 37 & 283 \\
\hline $\begin{array}{l}\mathrm{Ti}-37.5 \mathrm{Nb}- \\
6.25 \mathrm{Zr}\end{array}$ & 827 & 30 & 222 & $\begin{array}{l}\mathrm{Ti}-31.25 \mathrm{Nb}- \\
25 \mathrm{Ta}\end{array}$ & 847 & 30 & 234 \\
\hline $\begin{array}{c}\mathrm{Ti}-37.5 \mathrm{Nb}- \\
12.5 \mathrm{Zr}\end{array}$ & 831 & 29 & 225 & $\begin{array}{c}\mathrm{Ti}-37.5 \mathrm{Nb}- \\
12.5 \mathrm{Ta}\end{array}$ & 936 & 32 & 259 \\
\hline $\begin{array}{c}\mathrm{Ti}-37.5 \mathrm{Nb}- \\
18.75 \mathrm{Zr}\end{array}$ & 842 & 30 & 227 & $\begin{array}{c}\mathrm{Ti}-37.5 \mathrm{Nb}- \\
18.75 \mathrm{Ta}\end{array}$ & 957 & 33 & 264 \\
\hline $\mathrm{Ti}-50 \mathrm{Nb}$ & 855 & 31 & 232 & & & & \\
\hline $\mathrm{Ti}-18.75 \mathrm{Nb}$ & 755 & 26 & 196 & & & & \\
\hline $\begin{array}{l}\mathrm{Ti}-18.75 \mathrm{Nb}- \\
6.25 \mathrm{Zr}\end{array}$ & 679 & 24 & 183 & & & & \\
\hline $\begin{array}{c}\mathrm{Ti}-18.75 \mathrm{Nb}- \\
31.25 \mathrm{Zr}\end{array}$ & 788 & 28 & 207 & & & & \\
\hline
\end{tabular}

$f(x)=\frac{b}{\pi}\left(\tan ^{-1}\left(\frac{x}{\xi}\right)\right)+\frac{b}{2}$,

where $b$ is the magnitude of the Burgers vector of the slip dislocation, $x$ is the position of the dislocation line, and $\xi$ is the half-core width of the dislocation given by $d /(2(1-v))$ [26], where $d$ is the $\{001\}$ interplanar distance, and $v$ is the Poisson ratio. The discrete form of Eq. (1) can be written as 


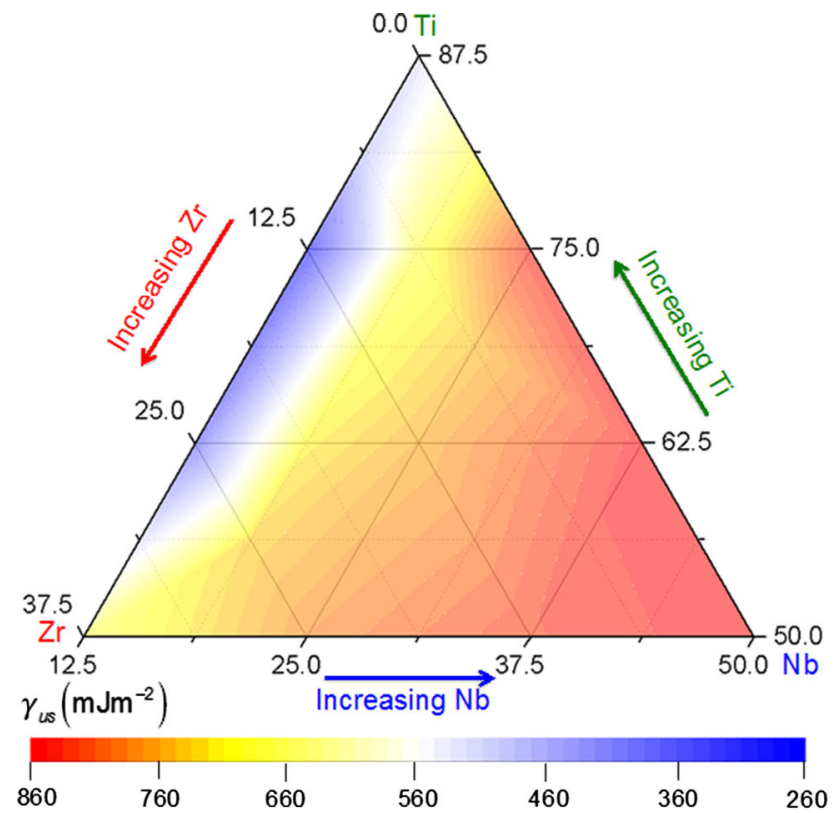

(a)

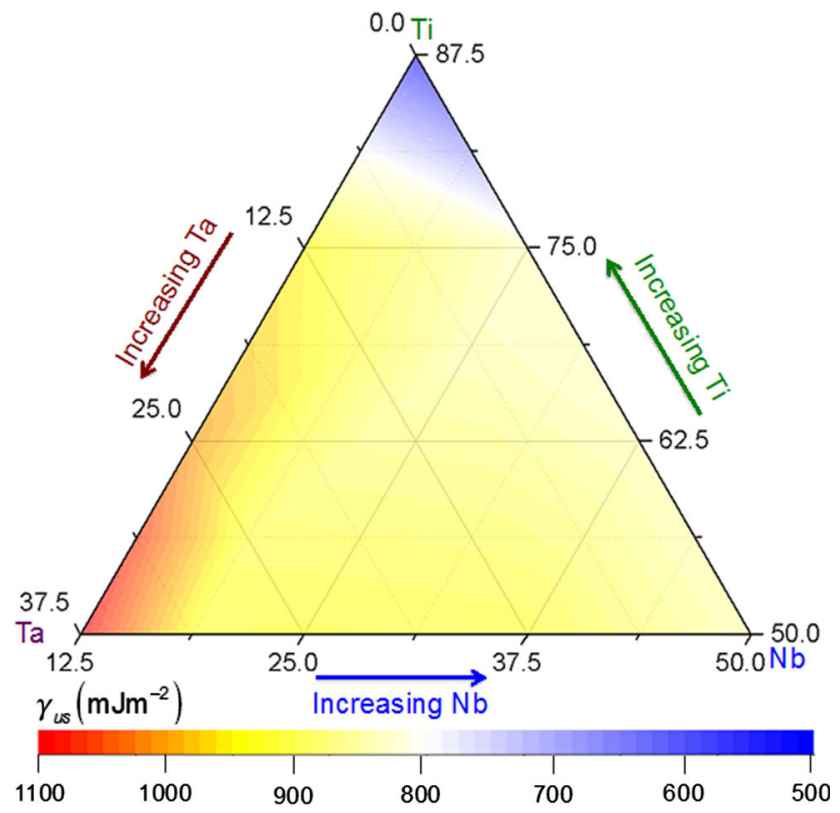

(b)

Fig. 9 Composition dependence of unstable fault energy in a $\mathrm{Ti}-\mathrm{Nb}-\mathrm{Zr}$, b $\mathrm{Ti}-\mathrm{Nb}-\mathrm{Ta}$ alloys

Fig. 10 a Schematic of the PN model for slip nucleation. b Misfit energy $\left(E_{\gamma}^{\mathrm{s}}\right)$ variation with respect to the dislocation position for the case of $\mathrm{Ti}-$ $6.25 \mathrm{Nb}-25 \mathrm{Ta}$

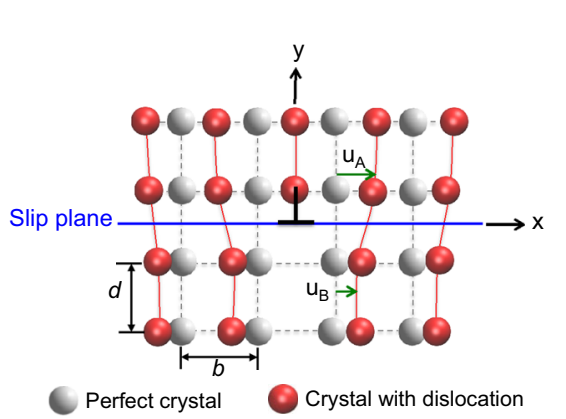

(a)

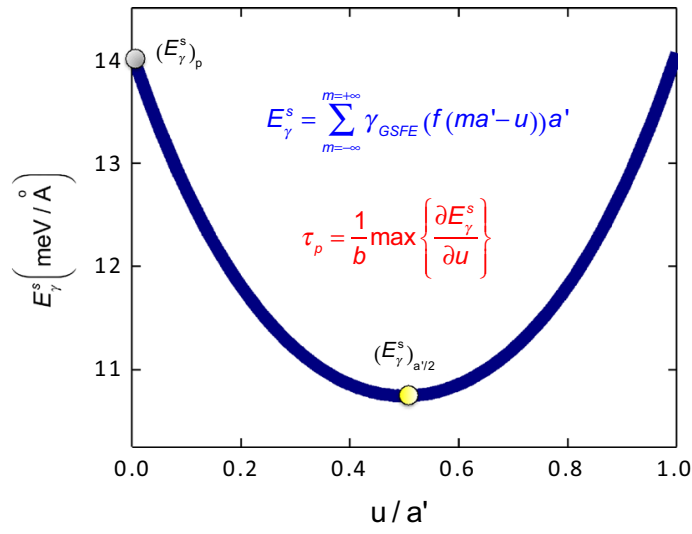

(b)
$E_{\gamma}^{\mathrm{s}}=\sum_{m=-\infty}^{m=+\infty} \gamma_{\mathrm{GSFE}}\left(f\left(m a^{\prime}-u\right)\right) a^{\prime}$

where $m$ is an integer, $u$ is the position of the dislocation line, and $a^{\prime}$ is the lattice periodicity defined as the shortest distance between two equivalent atomic rows in the direction of the dislocation displacement. The numerical solution to Eq. (3) for the case of Ti-6.25Nb-25Ta is shown in Fig. 10b. In Fig. 10b, the term $\left(E_{\gamma}^{\mathrm{s}}\right)_{a^{\prime} / 2}$ is the minimum of the $E_{\gamma}^{\mathrm{s}}$ function and provides an estimate of the core energy of the dislocation. Similarly, the term $\left(E_{\gamma}^{\mathrm{s}}\right)_{p}$ is the Peierls energy (marked on Fig. 10b) which is the amplitude of the variation and the barrier required to move the dislocation. The Peierls stress is calculated as the maximum slope of the misfit energy curve which describes the potential energy of the dislocation as a function of the dislocation position $u$ [26], and can be written as follows:

$\tau_{\text {critical }}^{\text {slip }}=\max \left\{\frac{1}{b}\left(\frac{\partial E_{\gamma}^{\mathrm{s}}}{\partial u}\right)\right\}$

The values of the CRSS for slip using Eq. (4) are given in Table 3. We note that the $\gamma_{\text {us }}$ and ultimately the slip stress of $\mathrm{Ti}-\mathrm{Nb}-\mathrm{Ta}$ alloys are higher than $\mathrm{Ti}-\mathrm{Nb}-\mathrm{Zr}$ alloys for the same composition of $\mathrm{Ti}$ and $\mathrm{Nb}$. Therefore, higher the $\gamma_{\mathrm{us}}$, the higher is the CRSS obtained using Eq. (4). 


\section{Discussion and Implications of Results}

Figure 11 shows the magnitudes of the CRSS for martensite slip in $\mathrm{Ti}-\mathrm{Nb}-\mathrm{Zr}$ alloys for several compositions of $\mathrm{Nb}$ and $\mathrm{Zr}$. The results for the binary $\mathrm{Ti}-\mathrm{Nb}$ are also included. Two important observations are noted in the plot: (i) First, with an increase in $\mathrm{Nb}$ content, the CRSS for slip increases. The net increase in CRSS upon increasing $\mathrm{Nb}$ content from 6.25 to 12.5 at.\% for a constant $\mathrm{Zr}$ content is within $40 \mathrm{MPa}$, while a dramatic increase in the stress (approximately $60 \%$ ) is observed upon increasing $\mathrm{Nb}$ content from 12.5 to 18.75 at.\%. (ii) Secondly, the results show that a critical $\mathrm{Zr}$ content exists for each $\mathrm{Nb}$ content beyond which the magnitude of CRSS for slip increases with an increase in $\mathrm{Zr}$ content. For $6.25,12.5,18.75,25$, and 37.5 at.\% $\mathrm{Nb}$ contents, the slip stress increases linearly with an increase in $\mathrm{Zr}$ content beyond 12.5, 12.5, 6.25, 6.25, and 6.25 at.\%, respectively.

We note that $\mathrm{Ti}-24 \mathrm{Zr}-13 \mathrm{Nb}$ does not exhibit superelasticity, as validated by experiments [8], and the reason behind this may be due a low CRSS for slip compared to the martensite transformation stress. For example, the calculated CRSS of $\mathrm{Ti}-25 \mathrm{Zr}-12.5 \mathrm{Nb}$ in the present analysis, which has a similar composition to $\mathrm{Ti}-24 \mathrm{Zr}-13 \mathrm{Nb}$, is $125 \mathrm{MPa}$. In such a case, it is easier to deform by slip than to induce martensite transformation, and this accumulates the permanent irreversible strain. On the other hand, for the case of $\mathrm{Ti}-25 \mathrm{Nb}$, it is experimentally observed that the transformation strain of approximately $2.2 \%$ is fully recovered [8]. This can be a result of the high CRSS for slip nucleation. Theoretically, we obtained the CRSS of $228 \mathrm{MPa}$ for the case of $\mathrm{Ti}-25 \mathrm{Nb}$, a $113 \%$ increase in the CRSS compared to $\mathrm{Ti}-12.5 \mathrm{Nb}-25 \mathrm{Zr}$ where no

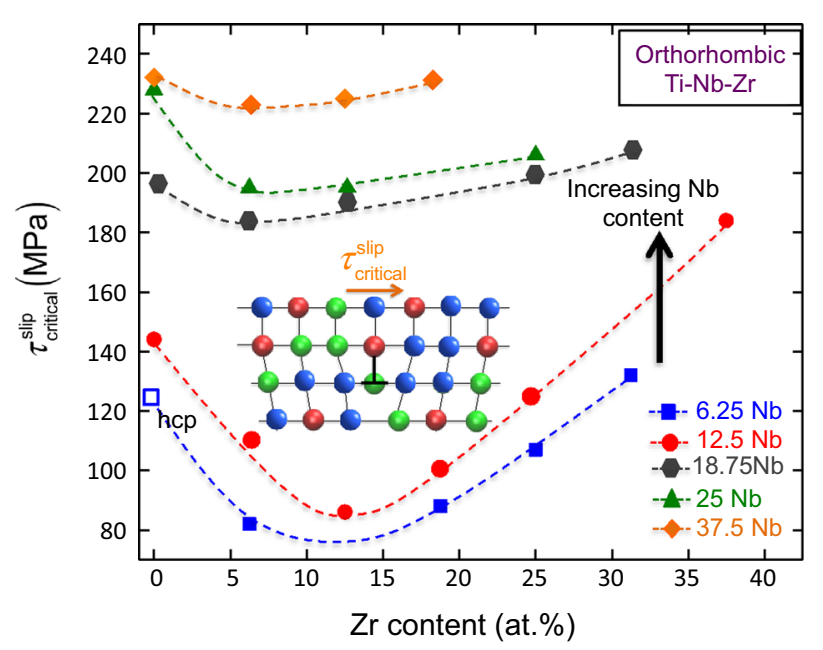

Fig. 11 CRSS for martensite slip nucleation as a function of $\mathrm{Zr}$ content in $\mathrm{Ti}-\mathrm{Nb}-\mathrm{Zr}$ alloys. The CRSS for hcp Ti-6.25Nb martensite nucleation is also shown (as open square) pseudoelasticity was observed. Hence, from the present analysis, the magnitude of the CRSS can be related to the recoverability of $\mathrm{Ti}-\mathrm{Nb}$-based alloys to a first approximation. In other words, the higher slip resistance favors martensite transformation, thereby inhibiting nucleation and accumulation of martensite slip. Nonetheless, the difference in the CRSS for slip and the martensite transformation stress is another important factor to consider.

Similarly, Fig. 12 shows the effect of $\mathrm{Nb}$ and Ta contents on the CRSS for Ti-Nb-Ta alloys. Here, we point to the major difference between the role of Ta compared to $\mathrm{Zr}$ on the CRSS for slip. We observe that the addition of Ta content on binary $\mathrm{Ti}-\mathrm{Nb}$ alloys increases the CRSS for slip. For example, the CRSS for slip for Ti-12.5Nb is $144 \mathrm{MPa}$ while that of Ti-12.5Nb-12.5Ta is $263 \mathrm{MPa}$, an increase in the slip stress by more than $80 \%$ with 12.5 at.\% Ta addition. While for the same composition of $\mathrm{Ti}$ and $\mathrm{Nb}$, the slip stress for Ti-12.5Nb-12.5Zr is $86 \mathrm{MPa}$, a decrease in the slip stress by $25 \%$. The initial decrease (or increase) of the slip stress upon alloying with $\mathrm{Zr}$ (or $\mathrm{Ta}$ ) has been reported previously in experiments $[9,10,12]$. The slip stress for binary $\mathrm{Ti}-22 \mathrm{Nb}$ is $370 \mathrm{MPa}$ while that of $\mathrm{Ti}-$ $22 \mathrm{Nb}-6 \mathrm{Zr}$ and $\mathrm{Ti}-22 \mathrm{Nb}-6 \mathrm{Ta}$ are approximately 310 and $440 \mathrm{MPa}$, respectively. It is important to note that the stresses reported experimentally are based on $0.2 \%$ strain offset, and do not correspond to the CRSS for slip. If we assume that the Schmid factor of the activated slip system is 0.5 , the CRSS for $\mathrm{Ti}-22 \mathrm{Nb}$ is $185 \mathrm{MPa}$ from experimental measurements. Overall, if we compare the magnitudes of the CRSS in $\mathrm{Ti}-\mathrm{Nb}-\mathrm{Ta}$ alloys compared to $\mathrm{Ti}-$ $\mathrm{Nb}-\mathrm{Zr}$ for the same composition of $\mathrm{Ti}$ and $\mathrm{Nb}$, we conclude that $\mathrm{Ta}$ is more effective in increasing martensite slip resistance than $\mathrm{Zr}$.

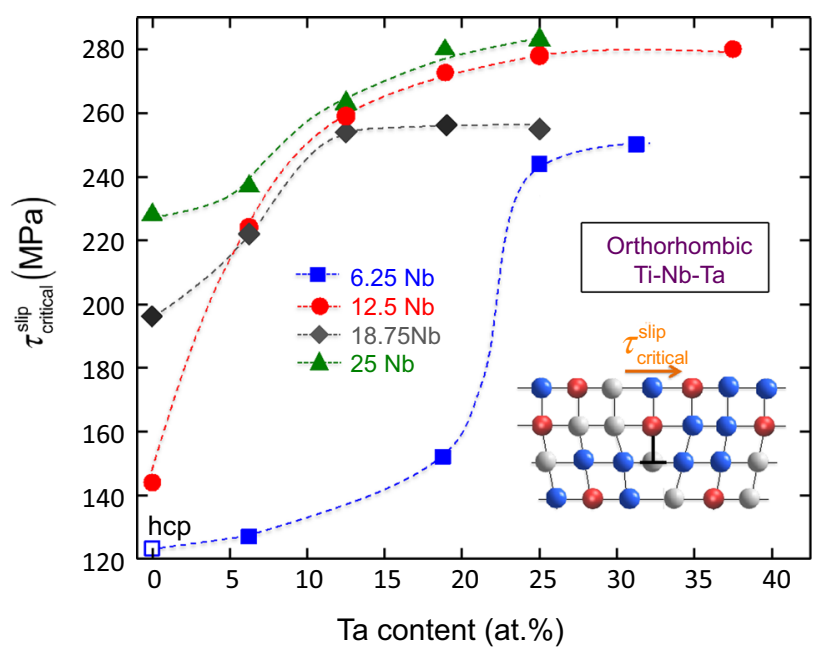

Fig. 12 CRSS for martensite slip nucleation as a function of $\mathrm{Ta}$ content in $\mathrm{Ti}-\mathrm{Nb}-\mathrm{Ta}$ alloys. The CRSS for hcp Ti-6.25Nb martensite nucleation is also shown (as open square) 
In the present work, we also calculated the maximum transformation strains based on the Lattice Deformation Theory (LDT) [28, 29] as shown in Figs. 13, 14, and 15. The details of the LDT are provided in "Appendix" section. In Fig. 13, we show the orientation dependence of the transformation strains for $\mathrm{Ti}-6.25 \mathrm{Nb}-6.25 \mathrm{Zr}$ and $\mathrm{Ti}-$ $6.25 \mathrm{Nb}-6.25 \mathrm{Ta}$ alloys. Note that two alloy compositions reported in Fig. 13 exhibit the highest transformation strains compared to all other alloys under consideration. It is worth pointing out that in all the alloy systems, the maximum transformation strain is observed in the [110] orientation, as in the case for $\mathrm{Ti}-6.25 \mathrm{Nb}-6.25 \mathrm{Zr}$ and $\mathrm{Ti}-$ $6.25 \mathrm{Nb}-6.25 \mathrm{Ta}$ (Fig. 13). The maximum transformation strain for $\mathrm{Ti}-6.25 \mathrm{Nb}-6.25 \mathrm{Zr}$ is $11 \%$ which is higher than that of $\mathrm{Ti}-6.25 \mathrm{Nb}-6.25 \mathrm{Ta}$ by $5 \%$. Upon comparing the maximum transformation strains in Figs. 13, 14, and 15, we conclude that $\mathrm{Zr}$ is a better alloying element compared to Ta for increasing the transformation strain.

We calculated the transformation strains for most of the alloy systems listed in Tables 2 and 3, and the maximum transformation strains are plotted in Figs. 14 and 15. From these plots, we observe that increasing $\mathrm{Nb}$ content in both $\mathrm{Ti}-\mathrm{Nb}-\mathrm{Ta}$ and $\mathrm{Ti}-\mathrm{Nb}-\mathrm{Zr}$ alloys for the same $\mathrm{Zr}$ or $\mathrm{Ta}$ content decreases the maximum transformation strain. This is in agreement with the experimental observations [10] for binary $\mathrm{Ti}-\mathrm{Nb}$ alloys where a decrease in transformation strain is seen with an increase in $\mathrm{Nb}$ content. It was found that an increase in $\mathrm{Nb}$ content from 15 to 25 at.\% decreases the transformation strain by $45 \%(4.5-2.5 \%)$. Interestingly, we observe that increase in $\mathrm{Zr}$ content increases the maximum transformation strain initially, but beyond a critical $\mathrm{Zr}$ content, the transformation strain starts to decrease. The critical $\mathrm{Zr}$ content is found to be 12.5 at.\% for all the alloys considered. On the other hand, no such critical Ta content exists for $\mathrm{Ti}-\mathrm{Nb}-\mathrm{Ta}$ alloys. Moreover, the maximum transformation strains of $\mathrm{Ti}-\mathrm{Nb}-\mathrm{Ta}$ alloys

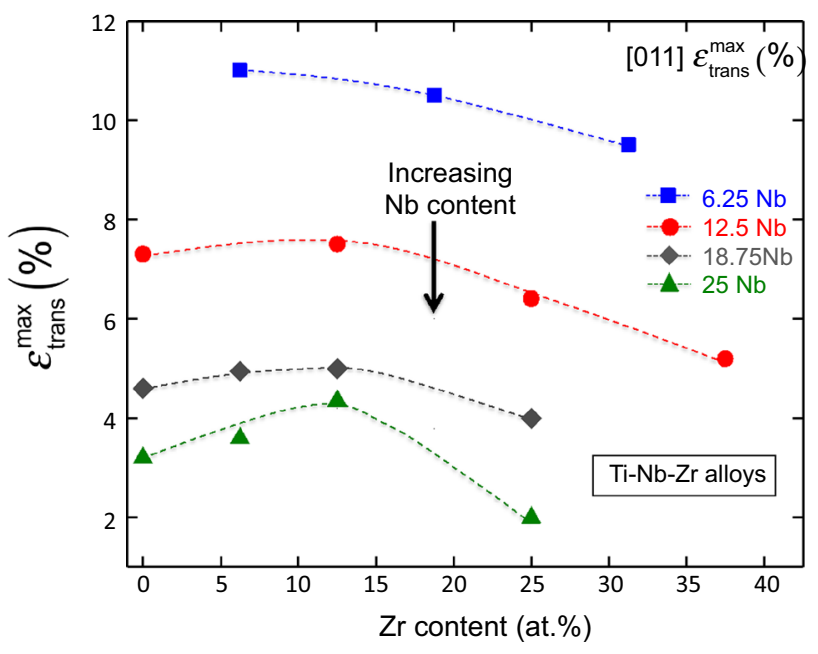

Fig. 14 The maximum [011] transformation strain (tension) as a function of $\mathrm{Zr}$ content in $\mathrm{Ti}-\mathrm{Nb}-\mathrm{Zr}$ alloys

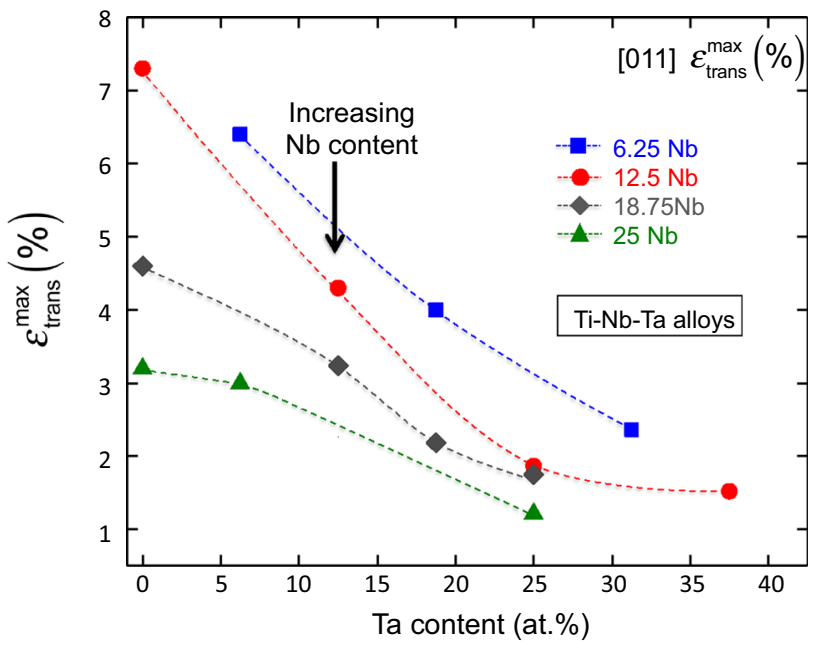

Fig. 15 The maximum [011] transformation strain (tension) as a function of $\mathrm{Ta}$ content in $\mathrm{Ti}-\mathrm{Nb}-\mathrm{Zr}$ alloys
Fig. 13 Orientation dependence of the transformation strain (tension) based on lattice deformation theory in a $\mathrm{Ti}-6.25 \mathrm{Nb}-6.25 \mathrm{Zr}$ and $\mathbf{b} \mathrm{Ti}-6.25 \mathrm{Nb}-6.25 \mathrm{Ta}$ alloys

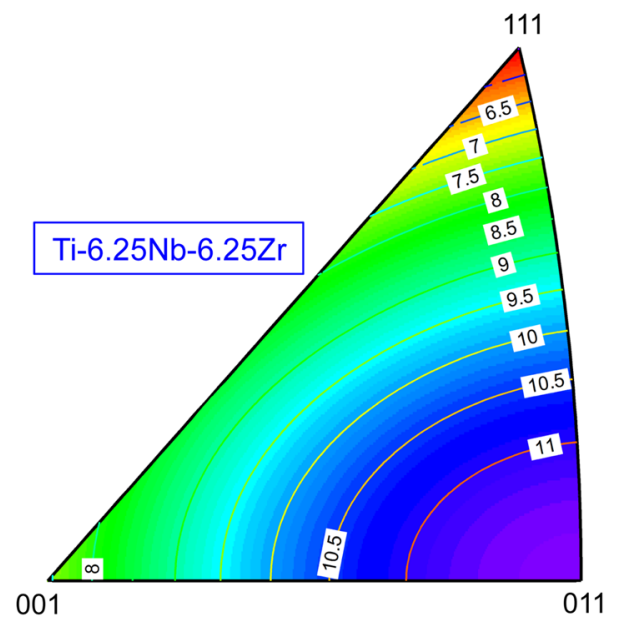

(a)

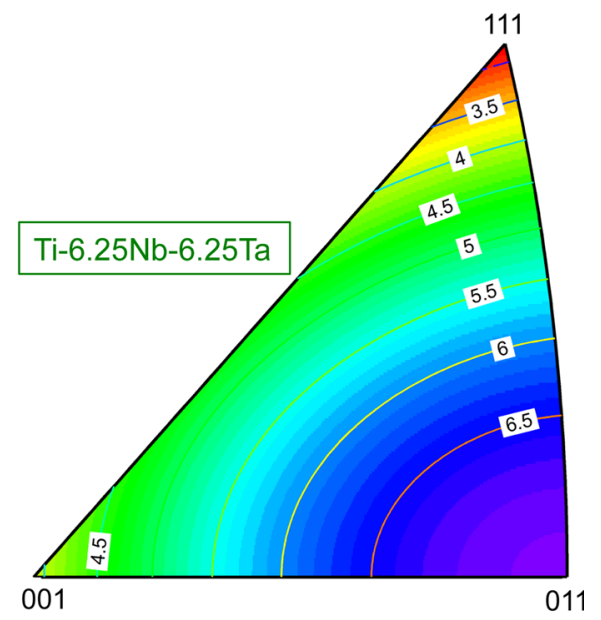

(b) 
are lower than those of $\mathrm{Ti}-\mathrm{Nb}-\mathrm{Zr}$ alloys for the same composition of $\mathrm{Ti}$ and $\mathrm{Nb}$.

We showed that the CRSS for slip is dictated by the unstable energy barrier of the GSFE curve using PN formalism. The higher the $\gamma_{\text {us }}$ value, the higher is the slip nucleation stress. Figure 16 shows that the CRSS for martensite slip nucleation in both $\mathrm{Ti}-\mathrm{Nb}-\mathrm{Ta}$ and $\mathrm{Ti}-\mathrm{Nb}-\mathrm{Zr}$ alloys shows a linear dependence on the unstable stacking fault energy value $\left(\gamma_{\text {us }}\right)$. This linear dependence can be expressed by the following equation:

$\tau_{\text {critical }}^{\text {slip }}\left(\gamma_{\text {us }}\right)=0.272 \times \gamma_{\text {us }}$

It is important to point out that the transformation strain scales approximately with $c / a_{0}$ ratio in $\mathrm{Ti}-\mathrm{Nb}$ alloys based on our calculations. We also showed that $\mathrm{Ta}$ and $\mathrm{Zr}$ do not exhibit similar effect on the CRSS and the transformation strains. Specially, we reveal a nonlinear dependence of the CRSS and the transformation strains on the $\mathrm{Ta}, \mathrm{Nb}$, and $\mathrm{Zr}$ contents. The critical compositions of $\mathrm{Zr}$ and Ta have been determined beyond which the martensite slip stress or the maximum transformation strains change (either increase or decrease). It is worth emphasizing that the CRSS values for slip obtained in the present analysis are at $0 \mathrm{~K}$, while experimental values are reported at finite temperatures. The reason for higher CRSS values obtained theoretically in the present case compared to the experimental values may be due to the temperature dependence of the elastic modulus of martensite. Experiment [30] has shown that a decrease in temperature (below $M \mathrm{~s}$ ) increases the martensite elastic modulus in Ti-based shape memory alloy, and therefore, Eq. (4) yields high CRSS at $0 \mathrm{~K}$ compared to the experimentally obtained CRSS values at finite temperatures. In summary, we considered the CRSS and the transformation

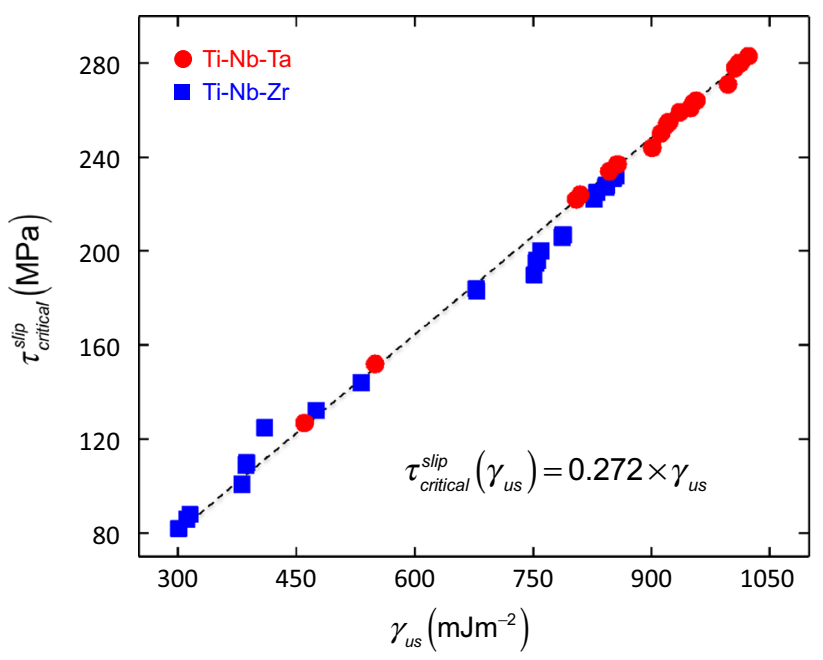

Fig. 16 The dependence of the CRSS for martensite slip nucleation $\left(\tau_{\text {critical }}^{\text {slip }}\right)$ on the unstable stacking fault energy values $\left(\gamma_{\mathrm{us}}\right)$ for $\mathrm{Ti}-\mathrm{Nb}-$

$\mathrm{Ta}$ and $\mathrm{Ti}-\mathrm{Nb}-\mathrm{Zr}$ alloys. The dashed line represents the best fit to data given by the equation in the inset strains for a large number of $\mathrm{Ti}-\mathrm{Nb}-\mathrm{Ta}$ and $\mathrm{Ti}-\mathrm{Nb}-\mathrm{Zr}$ alloys (over 40 cases) with wide composition range of Ta, $\mathrm{Zr}$, and $\mathrm{Nb}$. This is a major contribution to future alloy design via composition optimization.

\section{Conclusions}

In summary, we draw the following conclusion from the current paper:

1. Using modified PN formalism incorporating the generalized stacking fault energy (GSFE) from DFT calculations, we predict the martensite slip resistance in $\mathrm{Ti}-$ $\mathrm{Nb}-\mathrm{Ta}$ and $\mathrm{Ti}-\mathrm{Nb}-\mathrm{Zr}$ alloys over wide composition of $\mathrm{Nb}$, Ta, and $\mathrm{Zr}$. The CRSS levels are in the range 80-280 MPa. We propose a simple linear relation between the CRSS and unstable fault energy.

2. We calculate the lattice constants of $\mathrm{Ti}-\mathrm{Ta}-\mathrm{Nb}$ and $\mathrm{Ti}-$ $\mathrm{Nb}-\mathrm{Zr}$ for $\beta$ and $\alpha^{\prime \prime} \mathrm{B} 19$ orthorhombic structures noting that the superelasticity in these alloys is attributed to the thermoelastic transformation between the two phases. We compare our theoretically obtained values with the available experimental data showing excellent agreement.

3. Using lattice deformation theory (LDT), we calculate the maximum transformation strains in both $\mathrm{Ti}-\mathrm{Nb}-\mathrm{Ta}$ and $\mathrm{Ti}-\mathrm{Nb}-\mathrm{Zr}$ alloys. We show that the maximum transformation strain is higher in the case of $\mathrm{Ti}-\mathrm{Nb}-\mathrm{Zr}$ alloys compared to $\mathrm{Ti}-\mathrm{Nb}-\mathrm{Ta}$ alloys for the same composition of $\mathrm{Ti}$ and $\mathrm{Nb}$. The strains exceed to $10 \%$ in some cases.

4. We show that the addition of $\mathrm{Zr}$ increases the transformation strain up to a critical $\mathrm{Zr}$ content beyond which the transformation strain starts to decrease. The maximum transformation strain is observed in the [011] orientation for all the alloys considered in the present analysis. Large additions of $\mathrm{Ta}$ and $\mathrm{Nb}$ decreases the maximum transformation strain in the alloys from $11 \%$ to as low as $1.5 \%$.

5. From the present analysis, $\mathrm{Ta}$ is considered more effective in $\mathrm{Ti}-\mathrm{Nb}$ alloys in increasing the CRSS compared to $\mathrm{Zr}$, while $\mathrm{Zr}$ is more effective in increasing the transformation strain compared to Ta.

Acknowledgments The support from Nyquist Chair Fund and partial support from National Science Foundation grant NSF CMMI1333884 are gratefully acknowledged. We thank Mr. George Li for providing assistance with the LDT simulations setup.

\section{Appendix}

The Lattice Deformation Theory (LDT) [29] estimates the recoverable transformation strains by directly considering the 6 lattice correspondences between the bcc austenite and 
the orthorhombic martensite crystal structures. For each lattice correspondence variant, a symmetric transformation matrix $\boldsymbol{U}$ can be determined. The components of $\boldsymbol{U}$ matrix are functions of the lattice constants of the parent austenite and transformed martensite phases. An example of $\boldsymbol{U}$ for the case of cubic to orthorhombic transformation is

$\boldsymbol{U}_{1}=\left[\begin{array}{ccc}\alpha & 0 & 0 \\ 0 & \frac{\gamma+\beta}{2} & \frac{\gamma-\beta}{2} \\ 0 & \frac{\gamma-\beta}{2} & \frac{\gamma+\beta}{2}\end{array}\right]$,

where $\alpha=\sqrt{2} a / a_{0}, \beta=b / a_{0}, \gamma=\sqrt{2} c / a_{0}, a_{0}$, and $a, b$, and $c$ are the lattice constants of the bcc austenite and the orthorhombic martensite phases, respectively.

The maximum recoverable strains is obtained as

$\varepsilon=\sqrt{\vec{e} \cdot\left(\boldsymbol{F}^{T} \boldsymbol{F}\right) \vec{e}}-1$,

where $\boldsymbol{F}$ is the deformation gradient and $\vec{e}$ is the unit vector in the crystallographic direction of interest. Using polar decomposition theorem, the deformation gradient $\boldsymbol{F}$ can be written as

$F=\boldsymbol{R} \boldsymbol{U}$,

where $\boldsymbol{R}$ represents a rigid body rotation and $\boldsymbol{U}$ is the symmetric part of $\boldsymbol{F}$.

Upon substituting Eq. (8) into Eq. (7), we have the following equivalent equation:

$\varepsilon=\sqrt{\vec{e} \cdot\left(\boldsymbol{U}^{T} \boldsymbol{R}^{T} \boldsymbol{R} \boldsymbol{U}\right) \vec{e}}-1=\sqrt{\vec{e} \cdot\left(\boldsymbol{U}^{T} \boldsymbol{U}\right) \vec{e}}-1$

\section{References}

1. Baker C (1971) Shape memory behavior in Ti-35 wt $\% \mathrm{Nb}$ alloy. J Met Sci 5:92-100

2. Duerig TW, Albrecht J, Richter D, Fischer P (1982) Formation and reversion of stress induced martensite in Ti-10 V-2Fe-3Al. Acta Metall 30:2161-2172

3. Duerig TW, Richter DF, Albrecht J (1982) Shape memory in Ti10 V-2Fe-3Al. Scr Metall 16:957-961

4. Blackburn MJ, Feeney JA (1970) Stress-induced transformations in Ti-Mo alloys. DTIC Document

5. Hochstuhl P, Obst B (1982) Beta-phase instability and martensitic transformation in Ti-22 a/o Nb alloy. Le Journal de Physique Colloques 43:C4-133-C4-138

6. Ozaki T, Matsumoto H, Watanabe S, Hanada S (2004) Beta Ti alloys with low Young's modulus. Mater Trans 45:2776-2779

7. Hao YL, Li SJ, Sun SY, Zheng CY, Hu QM, Yang R (2005) Super-elastic titanium alloy with unstable plastic deformation. Appl Phys Lett 87:091906
8. Kim HY, Fu J, Tobe H, Kim JI, Miyazaki S (2015) Crystal structure, transformation strain, and superelastic property of Ti$\mathrm{Nb}-\mathrm{Zr}$ and $\mathrm{Ti}-\mathrm{Nb}-\mathrm{Ta}$ alloys. Shape Mem Superelast 1:107-116

9. Kim HY, Hashimoto S, Kim JI, Inamura T, Hosoda H, Miyazaki $\mathrm{S}$ (2006) Effect of Ta addition on shape memory behavior of Ti22Nb alloy. Mater Sci Eng A 417:120-128

10. Kim HY, Ikehara Y, Kim JI, Hosoda H, Miyazaki S (2006) Martensitic transformation, shape memory effect and superelasticity of Ti-Nb binary alloys. Acta Mater 54:2419-2429

11. Miyazaki S, Kim HY, Hosoda H (2006) Development and characterization of $\mathrm{Ni}$-free $\mathrm{Ti}$-base shape memory and superelastic alloys. Mater Sci Eng A 438:18-24

12. Kim JI, Kim HY, Inamura T, Hosoda H, Miyazaki S (2005) Shape memory characteristics of $\mathrm{Ti}-22 \mathrm{Nb}-(2-8) \mathrm{Zr}$ (at.\%) biomedical alloys. Mater Sci Eng A 403:334-339

13. Karaman I, Sehitoglu H, Beaudoin AJ, Chumlyakov YI, Maier HJ, Tome CN (2000) Modeling the deformation behavior of Hadfield steel single and polycrystals due to twinning and slip. Acta Mater 48:2031-2047

14. Kresse G, Furthmüller J (1996) Efficient iterative schemes for ab initio total-energy calculations using a plane-wave basis set. Phys Rev B 54:11169-11186

15. Kresse G, Hafner J (1993) Ab initio molecular dynamics for open-shell transition metals. Phys Rev B 48:13115-13118

16. Banerjee D, Rowe RG, Hall EL (1990) Deformation of the orthorhombic phase in $\mathrm{Ti}-\mathrm{Al}-\mathrm{Nb}$ alloys. MRS Proceedings. Cambridge University Press, Cambridge, p 285

17. Poirier J-P (1975) On the slip systems of olivine. J Geophys Res 80:4059-4061

18. Vitek V (1968) Intrinsic stacking faults in body-centred cubic crystals. Philos Mag 18:773-786

19. Ojha A, Sehitoglu H (2014) Twinning stress prediction in bcc metals and alloys. Philos Mag Lett 94:647-657

20. Ojha A, Sehitoglu H, Patriarca L, Maier HJ (2014) Twin nucleation in Fe-based bcc alloys-modeling and experiments. Modell Simul Mater Sci Eng 22:075010

21. Wang J, Sehitoglu H (2014) Modelling of martensite slip and twinning in NiTiHf shape memory alloys. Phil Mag 94:2297-2317

22. Lu G, Kioussis N, Bulatov VV, Kaxiras E (2000) The peierlsnabarro model revisited. Philos Mag Lett 80:675-682

23. Peierls R (1940) The size of a dislocation. Proc Phys Soc 52:34

24. Carrez P, Ferré D, Cordier P (2007) Peierls-Nabarro model for dislocations in $\mathrm{MgSiO} 3$ post-perovskite calculated at $120 \mathrm{GPa}$ from first principles. Philos Mag 87:3229-3247

25. Joos B, Duesbery MS (1997) The Peierls stress of dislocations: an analytic formula. Phys Rev Lett 78:266

26. Joós B, Ren Q, Duesbery MS (1994) Peierls-Nabarro model of dislocations in silicon with generalized stacking-fault restoring forces. Phys Rev B 50:5890-5898

27. Schoeck G (2011) The Peierls stress in a simple cubic lattice. Phys Status Solidi (b) 248:2284-2289

28. Bhattacharya K (2003) Microstructure of martensite: why it forms and how it gives rise to the shape-memory effect. Oxford University Press, Oxford

29. Saburi T, Nenno S (1981) The shape memory effect and related phenomena. Solid to solid phase transformations. The Metallurgical Society of AIME, New York, pp 1455-1479

30. Inamura T, Hosoda H, Wakashima K, Miyazaki S (2005) Anisotropy and temperature dependence of Young's modulus in textured TiNbAl biomedical shape memory alloy. Mater Trans 46:1597-1603 